\title{
GAS FILLING IN GLASS SYSTEM
}

\author{
SILVIA BIZOŇOVÁ*, MILOSLAV BAGOŇA \\ Faculty of Civil Engineering, Technical University of Košice, Vysokoškolská 4, 04200 Košice, Slovakia \\ *E-mail: silvia.bizonova@tuke.sk
}

\begin{abstract}
The filler structure is one of the most critical parts of the building's envelope so great emphasis should be placed on its proper design. In addition to the number of panes in the glass system, material of the spacer, the type and the concentration of the filler gas in the cavity between glasses of the insulated system as well as the size of the cavity are also important. The paper focuses on the assessment of the influence of filler gas in the glass system cavity to the energy features of the glass structure. The reason for the assessment is the key influence of the inert gas and the glass cavity dimension on the energy properties of the glass system and the fact that its gradually decreasing concentration greatly affects the properties of the glass system.
\end{abstract}

Keywords: filler gas, gas space width, energy features, heat transfer

\section{Introduction}

The paper deals with the effect of the type and concentration of the filler gas between the glass panes on the deformation of thermal field. The transparent structure consists of a frame and glass system. The glass system accounts for up to $80 \%$ of the total area of the transparent structure, indicating that it has a key effect on the energy properties of the entire structure. The number of glass panes, the type and concentration of fill gas in the gap between the glasses, the use of selective layers and coatings, and the spacer bar material, enter the notional formula.

At present, the most commonly used triple insulating glass systems compared to insulating double glass systems have significantly improved energy properties due to the addition of additional pane and gas-filled gap. An important role in this case is also replacement of air as a gap filling with inert gas. In particular, the inert gas provides mentioned properties. However, the glass system filled with inert gas as a result of the degradation of sealing materials loses its insulating properties and gas leak occurs, which lead to a reduction in the energy properties of the entire transparent structure. Permissible annual gas leakage from the glass system is $1 \%$ [1]. However, the gas leakage is not constant in time, therefore the decrease is not linear, depends on several aspects such as used sealants, rate of degradation and other side influences. Numerical analysis using computer software represents an effective method of detecting the influence of the filling gas concentration on the thermal insulating ability of the glass system and then impact on the analyzed thermal field. Using dynamic or stationary softwares allows the application of complex mathematical-physical theories [2]. Decreasing the surface temperature on the inner surface can lead to condensation, so it is essential to maintain the lowest surface temperature of the structure safely above the dew point temperature $\theta_{d p}$. Minimum surface temperature of transparent structures (frames, non-transparent and transparent opening panels) in areas with relative air humidity up to $50 \%$ must be $\theta_{s i, w}[3]$ :

$$
\theta_{s i, w}>\theta_{s i, w, N}=\theta_{d p},
$$

where $\theta_{s i, w, N}\left({ }^{\circ} \mathrm{C}\right)$ is the minimal required inside surface temperature value of transparent envelope parts, $\theta_{d p}$ $\left({ }^{\circ} \mathrm{C}\right)$ the dew point temperature, $\theta_{\text {si, }}\left({ }^{\circ} \mathrm{C}\right)$ the inside surface temperature of transparent envelope part.

This is an open-access article distributed under the terms of the Creative Commons Attribution-NonCommercial 4.0 International License (https://creativecommons.org/licenses/by-nc/4.0/), which permits unrestricted use, distribution, and reproduction in any medium for non-commercial purposes, provided the original author and source are credited, a link to the CC License is provided, and changes - if any - are indicated. 
The purpose of this analysis is to compare the six concepts of the glass system, differing in the use of filler gas in the gap between the glasses and width of gap. The analysis leads to determining the dependence of the thermal insulation properties on the filling gas concentration. Furthermore, it is necessary to quantify the change in surface temperature over the glazing circumference over time and subsequently to locate the point with the lowest surface temperature based on the thermal field. The influence of water vapor is not considered.

The measurement of filler gas concentration in real conditions is complicated. This parameter of the glass system implicitly expresses the heat transfer coefficient $U_{g}$. There are several ways to determine $U_{g}$. The first option is the calculation according to STN EN 673 [4], another option is the measurement according to STN EN 674 [5] or according to STN EN 675 [6]. Harmonized EN 1279+5+A1 imposes an obligation to express $U_{g}$ by calculation method according to STN EN 673. The procedure according to STN EN
674 or STN EN 675 can only be used if $U_{g}$ cannot be determined by calculation [7].

\section{Designed detail of window}

Frame construction. Selected is aluminium nonwelding with interrupted thermal bridge. Frame depth is $112 \mathrm{~mm}$ in all considered cases. Heat transfer coefficient of frame $U_{f}$ is $0.72 \mathrm{~W} / \mathrm{m}^{2} \cdot \mathrm{K}$. The following frame parameters are considered for simulation in Physibel - Bistra: $\lambda=204 \mathrm{~W} / \mathrm{m} \cdot \mathrm{K} ; \rho=2700 \mathrm{~kg} / \mathrm{m}^{3}$; $c=880 \mathrm{~J} / \mathrm{kg} \cdot \mathrm{K}$.

Glass system. Conceived is as double and triple. Together, six different systems are designed, changing the filling gas (air, Argon, Krypton) and the thickness of the gap between the glasses depending on the filler gas used $(13,12,8 \mathrm{~mm})$. The concept of glass systems in which the gas concentration drops in such a way that the leaked gas is replaced by air

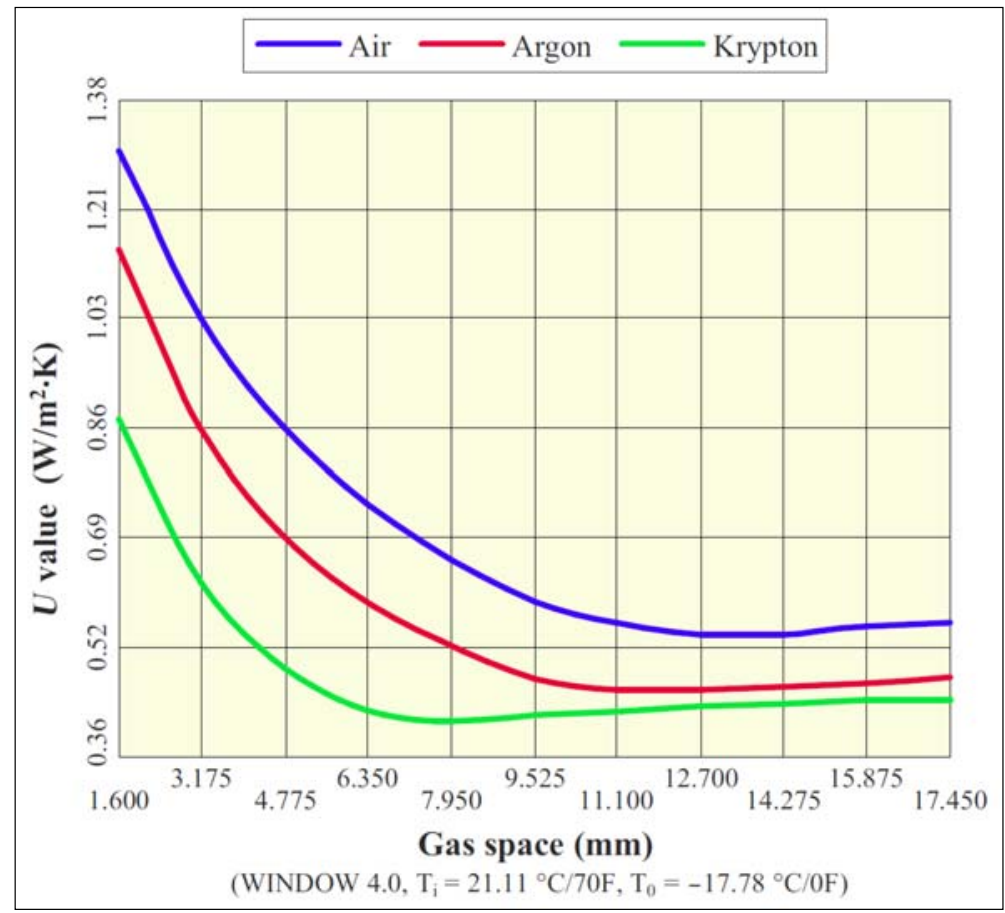

Fig. 1. Compositions of examined floor heating systems and thickness of layers

Table 1. Features of chosen gases

\begin{tabular}{lcc}
\hline Gas fill type $(100 \%)^{*}$ & $\begin{array}{c}\text { Optimum gas space width } \\
(\mathrm{mm})[3]\end{array}$ & $\begin{array}{c}\text { Thermal conductivity } \\
\text { coefficient } \lambda(\mathrm{W} / \mathrm{m} \cdot \mathrm{K})^{*}\end{array}$ \\
\hline Air & 13 & $2.496 \cdot 10^{-2}$ \\
Argon & 12 & $1.684 \cdot 10^{-2}$ \\
Krypton & 8 & $0.900 \cdot 10^{-2}$ \\
\hline
\end{tabular}

* Thermal conductivity coefficient of chosen gases is related to temperature $10{ }^{\circ} \mathrm{C}$ and concentration of $100 \%$ of gas, normalized boundary conditions used [4]. 
in the glass system, but under real conditions the gas would not be replaced by air, but a negative pressure would be created in the glass system. However, the software used does not allow this option.

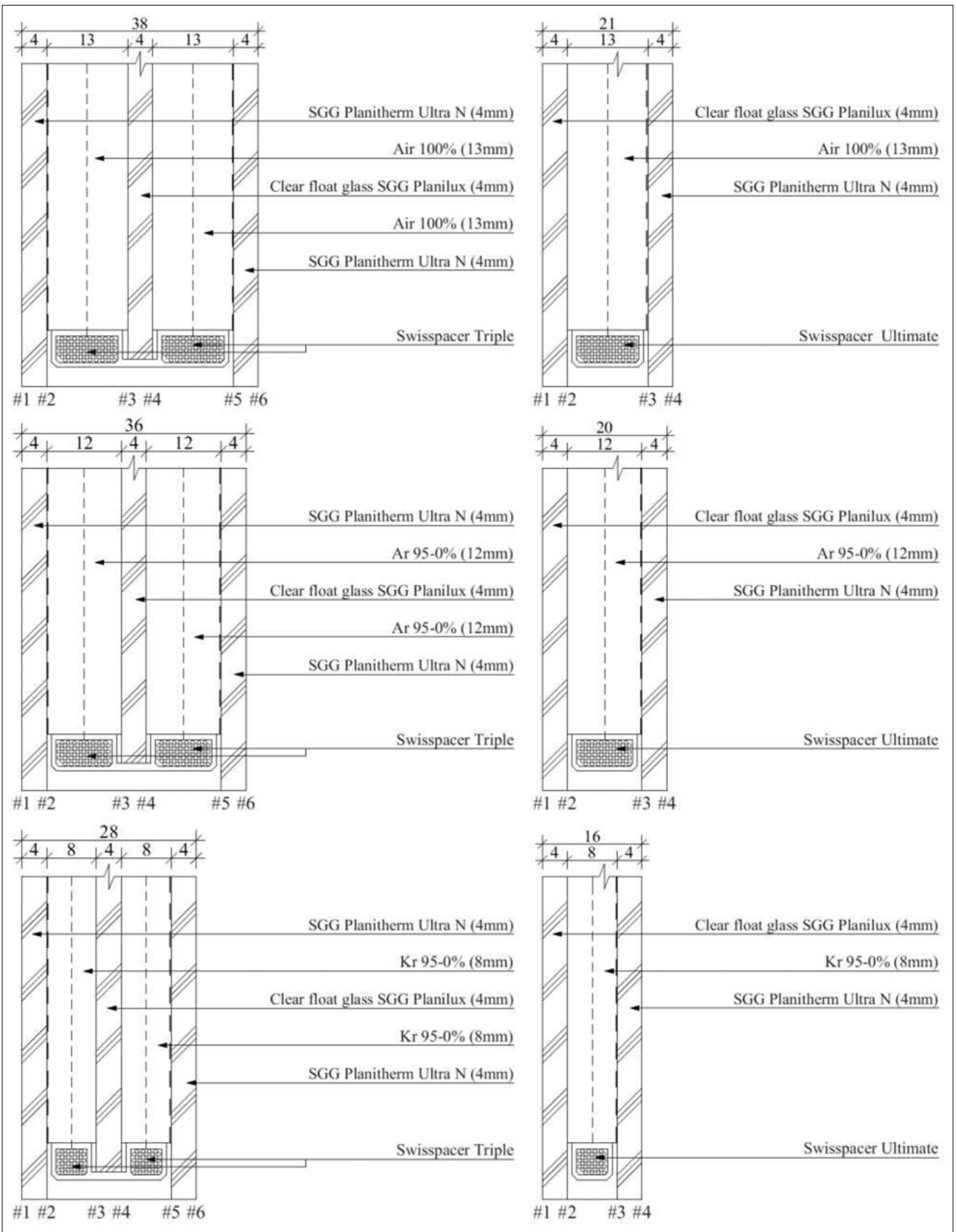

Fig. 2. Air filled triple and double glass system (A1, A2), Argon filled triple and double glass system (B1, B2), Krypton filled triple and double glass system $(\mathrm{C} 1, \mathrm{C} 2)$ 
Table 2. Composition os the structure of brick wall (layers are stated in direction from interior to exterior)

\begin{tabular}{|c|c|c|c|c|c|}
\hline No. & Name of layer & $D(\mathrm{~m})$ & $\lambda\left(\mathrm{W} / \mathrm{m}^{2} \cdot \mathrm{K}\right)$ & $c(\mathrm{~J} / \mathrm{kg} \cdot \mathrm{K})$ & $\rho\left(\mathrm{kg} / \mathrm{m}^{3}\right)$ \\
\hline 1 & Lime-cement plaster & 0.012 & 0.450 & 790.0 & 1350.0 \\
\hline 2 & Ceramic brick (mineral wool inside) & 0.440 & 0.066 & 1000.0 & 700.0 \\
\hline 3 & Silicone plaster & 0.015 & 0.700 & 900.0 & 1700.0 \\
\hline
\end{tabular}

Construction of wall. Composition of considered brick wall is in Table 2. Computed thermal transmittance of the wall is $U=0.15 \mathrm{~W} / \mathrm{m}^{2} \cdot \mathrm{K}$.

Boundary conditions. The design temperature for numerical analysis is given by calculation according to 73 0540-3 [9]; $\theta_{i}=20{ }^{\circ} \mathrm{C}$. There are several alternatives to selecting external design temperature. Consideration is given to the winter period so that it is possible to check the minimum temperature on the inner surface of the structure during the winter period. It is possible to consider the external design temperature according to the temperature range in which the structure is located; Kosice, Slovakia $\theta_{e}=-13{ }^{\circ} \mathrm{C}$ [9]. It is also possible to select the average design temperature for the most unfavourable month of the year from the thermal reference year. In this case, the most unfavourable month is December and the design temperature would be $3.1{ }^{\circ} \mathrm{C}[10]$. This reasoning is used for simulations in stationary boundary conditions. In the case of dynamic boundary conditions, temperatures measured over the time (for a certain period) would be used as in the case of research at the Faculty of Civil Engineering in Kosice, where researchers applied real values measured [11].

Selected structures. Final design is the result of combination partial segments described beforehand. In all cases is window frame seated in the middle of the ceramic brick. The same composition is used as well. Structures are varied in overall depth of glass system.

\section{Methodology}

Window 7.4.14 simulation software. Used computer program for calculating thermal performance of windows and other window properties. Window 7.4.14 [12] implements the ISO 15099 algorithms and includes additional functionalities.

Physibel software. Used for 2D heat transfer analysis [13]. Simulation is standard method to predict thermal performance of structure.

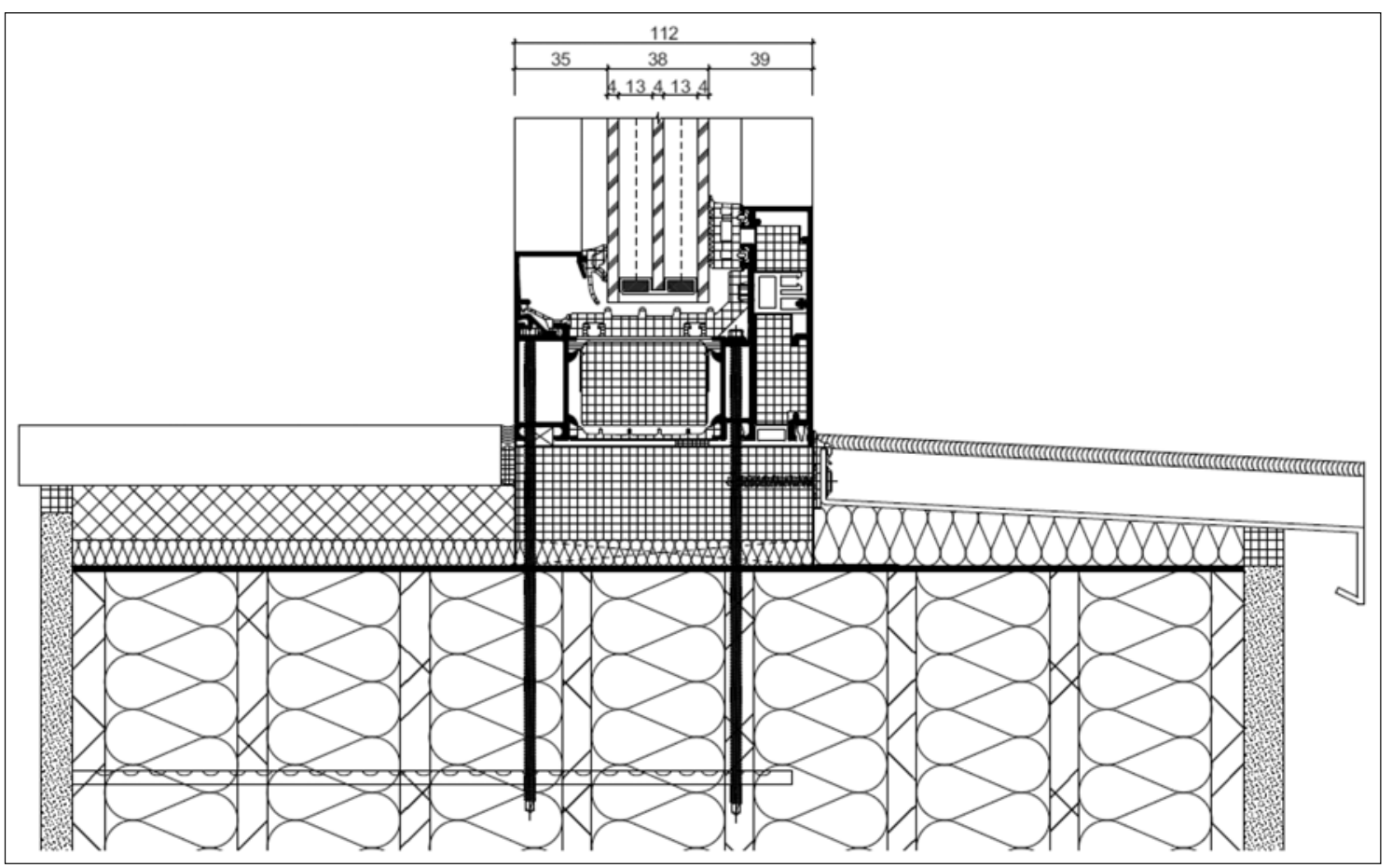

Fig. 3. Air filled triple glass system in aluminum frame seated in the middle of brick wall 
Table 3. Results of air filled triple and double glass system (A1, A2), Argon filled triple and double glass system (B1, B2), Krypton filled triple and double glass system (C1, C2)

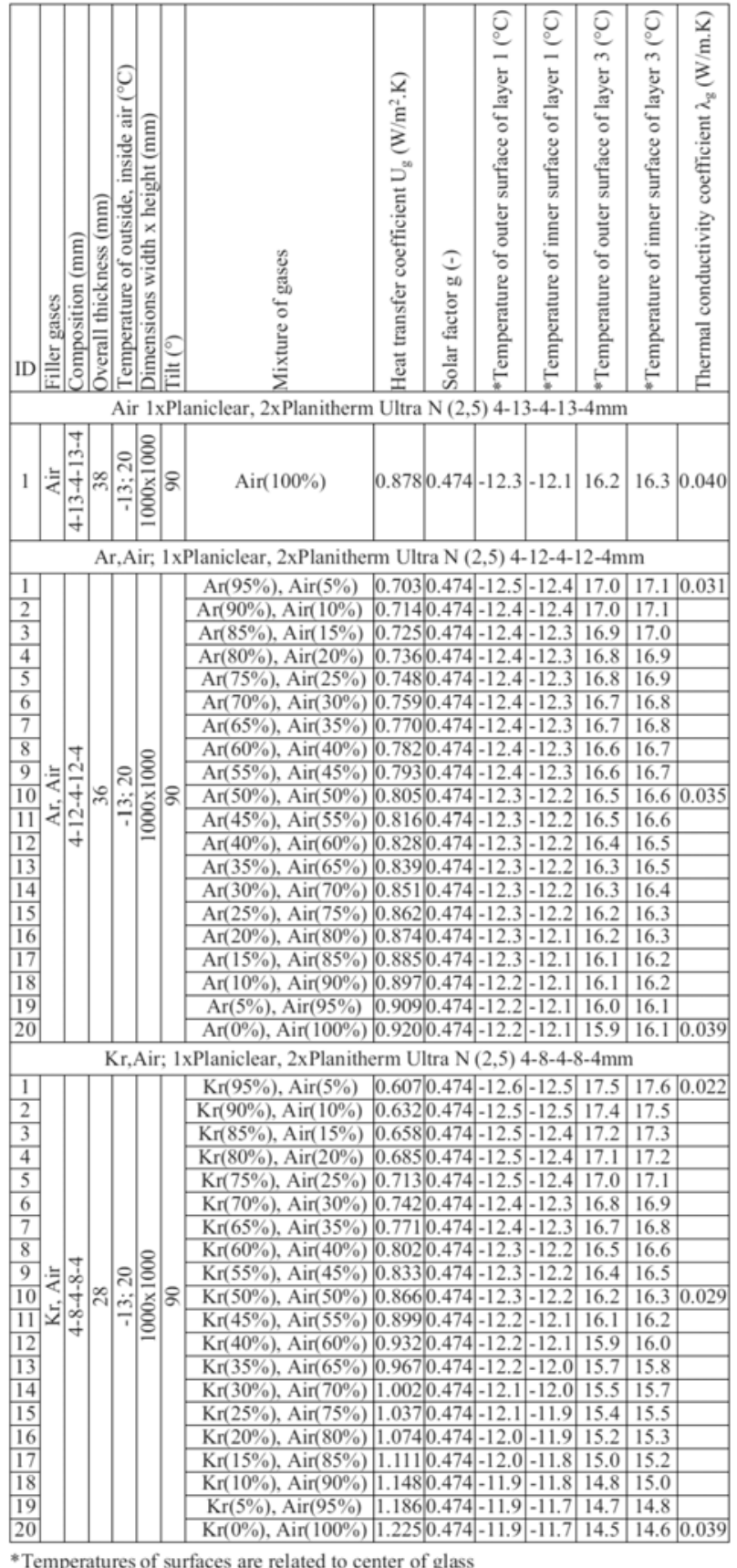

\section{Results}

The purpose of the analysis was to demonstrate the effect of the decrease of the concentration of the filling gas on the heat transfer coefficient of the glass system. In Tables 3 and 4 values of the heat transfer coefficient and the surface temperatures of individual glass surfaces are obtained from Window 7.4.14 calculation. Under the given boundary conditions and the physical model used, the surface temperature did not fall below $9.26{ }^{\circ} \mathrm{C}$ (dew point) nor in one of the

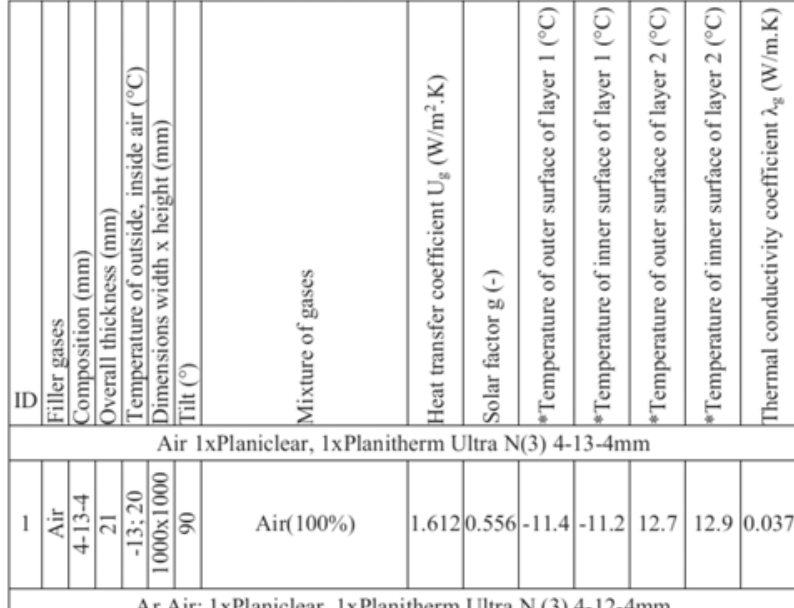

Ar,Air; 1xPlaniclear, 1xPlanitherm Ultra N (3) 4-12-4mm

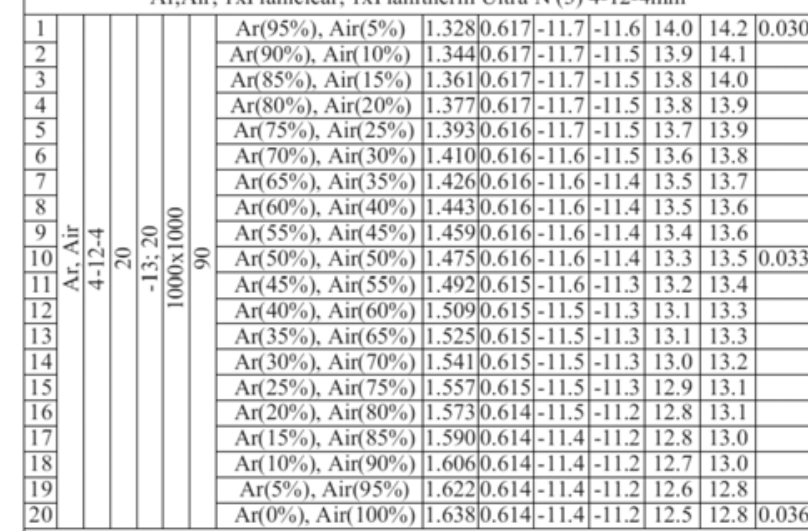
$\mathrm{Kr}$,Air; 1xPlaniclear, 1xPlanitherm Ultra N (3) $4-8-4 \mathrm{~mm}$

\begin{tabular}{|c|c|c|c|c|c|c|c|c|c|c|}
\hline 1 & & & \multirow{20}{*}{\multicolumn{2}{|c|}{ 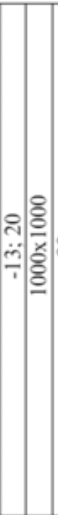 }} & $\operatorname{Kr}(95 \%), \operatorname{Air}(5 \%)$ & \begin{tabular}{|l|l|l|}
1.168 & 0.619 & -11.9 \\
\end{tabular} & -11.8 & $\mid 14.7$ & 14.9 & 0.021 \\
\hline 2 & & & & & $\operatorname{Kr}(90 \%), \operatorname{Air}(10 \%)$ & \begin{tabular}{|l|l|l|}
1.199 & 0.618 & -11.9 \\
\end{tabular} & -11.7 & 14.6 & 14.8 & \\
\hline 3 & & & & & $\operatorname{Kr}(85 \%), \operatorname{Air}(15 \%)$ & \begin{tabular}{|l|l|l|}
1.233 & 0.618 & -11.9 \\
\end{tabular} & -11.7 & 14.4 & 14.6 & \\
\hline 4 & & & & & $\operatorname{Kr}(80 \%), \operatorname{Air}(20 \%)$ & \begin{tabular}{|l|l|l|}
1.269 & 0.618 & -11.8 \\
\end{tabular} & -11.6 & 14.3 & 14.4 & \\
\hline 5 & & & & & $\operatorname{Kr}(75 \%), \operatorname{Air}(25 \%)$ & \begin{tabular}{|l|l|l|}
1.306 & 0.617 & -11.8 \\
\end{tabular} & -11.6 & 14.1 & 14.3 & \\
\hline 6 & & & & & $\operatorname{Kr}(70 \%), \operatorname{Air}(30 \%)$ & \begin{tabular}{|l|l|l|}
1.346 .616 & -11.7 \\
\end{tabular} & -11.5 & 13.9 & 14.1 & \\
\hline 7 & & & & & $\operatorname{Kr}(65 \%), \operatorname{Air}(35 \%)$ & $1.3870 .616-11.7$ & -11.5 & 13.7 & 13.9 & \\
\hline 8 & & & & & $\operatorname{Kr}(60 \%), \operatorname{Air}(40 \%)$ & \begin{tabular}{|l|l|l|l|}
1.430 .615 & -11.6 \\
\end{tabular} & -11.4 & 13.5 & 13.7 & \\
\hline 9 & & & & & $\operatorname{Kr}(55 \%), \operatorname{Air}(45 \%)$ & \begin{tabular}{|l|l|l|l|l|}
1.474 .615 & -11.6 \\
\end{tabular} & -11.4 & 13.3 & 13.5 & \\
\hline 10 & & & & & $\operatorname{Kr}(50 \%), \operatorname{Air}(50 \%)$ & $1.5190 .614-11.5$ & -11.3 & 13.1 & 13.3 & 0.02 \\
\hline 11 & & & & & $\operatorname{Kr}(45 \%), \operatorname{Air}(55 \%)$ & $1.565 \mid 0.614-11.5$ & -11.3 & 12.9 & 13.1 & \\
\hline 12 & & & & & $\operatorname{Kr}(40 \%), \operatorname{Air}(60 \%)$ & \begin{tabular}{|l|l|l|}
1.613 & 0.613 & -11.4 \\
\end{tabular} & -11.2 & 12.6 & 12.9 & \\
\hline 13 & & & & & $\operatorname{Kr}(35 \%), \operatorname{Air}(65 \%)$ & \begin{tabular}{|l|l|l|l|}
1.661 & 0.613 & -11.4 \\
\end{tabular} & -11.1 & 12.4 & 12.6 & \\
\hline 14 & & & & & $\operatorname{Kr}(30 \%), \operatorname{Air}(70 \%)$ & \begin{tabular}{|l|l|l|}
1.710 & 0.612 & -11.3 \\
\end{tabular} & -11.1 & 12.2 & 12.4 & \\
\hline 15 & & & & & $\operatorname{Kr}(25 \%), \operatorname{Air}(75 \%)$ & \begin{tabular}{|l|l|l|}
.760 & 0.612 & -11.2 \\
\end{tabular} & -11.0 & 11.9 & 12.2 & \\
\hline 16 & & & & & $\operatorname{Kr}(20 \%), \operatorname{Air}(80 \%)$ & $1.810|0.611|-11.2$ & -10.9 & 11.7 & 12.0 & \\
\hline 17 & & & & & $\operatorname{Kr}(15 \%), \operatorname{Air}(85 \%)$ & \begin{tabular}{|l|l|l|}
1.861 & 0.611 & -11.1 \\
\end{tabular} & -10.9 & 11.5 & 11.7 & \\
\hline 18 & & & & & $\operatorname{Kr}(10 \%), \operatorname{Air}(90 \%)$ & $1.912 \mid 0.610-11.1$ & -10.8 & 11.2 & 11.5 & \\
\hline 19 & & & & & $\operatorname{Kr}(5 \%), \operatorname{Air}(95 \%)$ & \begin{tabular}{|l|l|l|l|}
1.964 & 0.610 & -11.1 \\
\end{tabular} & -10.7 & 11.0 & 11.3 & \\
\hline 20 & & & & & $\operatorname{Kr}(0 \%), \operatorname{Air}(100 \%)$ & \begin{tabular}{|l|l|l|l|}
2.016 .609 & -11.0 \\
\end{tabular} & $\mid-10.7$ & 10.8 & 11.0 & 0.0 \\
\hline
\end{tabular}

cases considered, that is, in selected cases, a drop in the concentration of the filling gas to zero (in the glass system, insulating gas does not affect the thermal performance of the glass system to such an extent that condensation occurs on the surface of the transparent structure). Thermal insulating properties in the form of heat transfer coefficient have been impaired as a result of a decrease in the gas concentration in the glass system (see Table 5).

The values in the table show that the greatest influence on the heat transfer coefficient was mani- 
Table 4. Results of considered triple and double glass system in case of same width of gas filled space
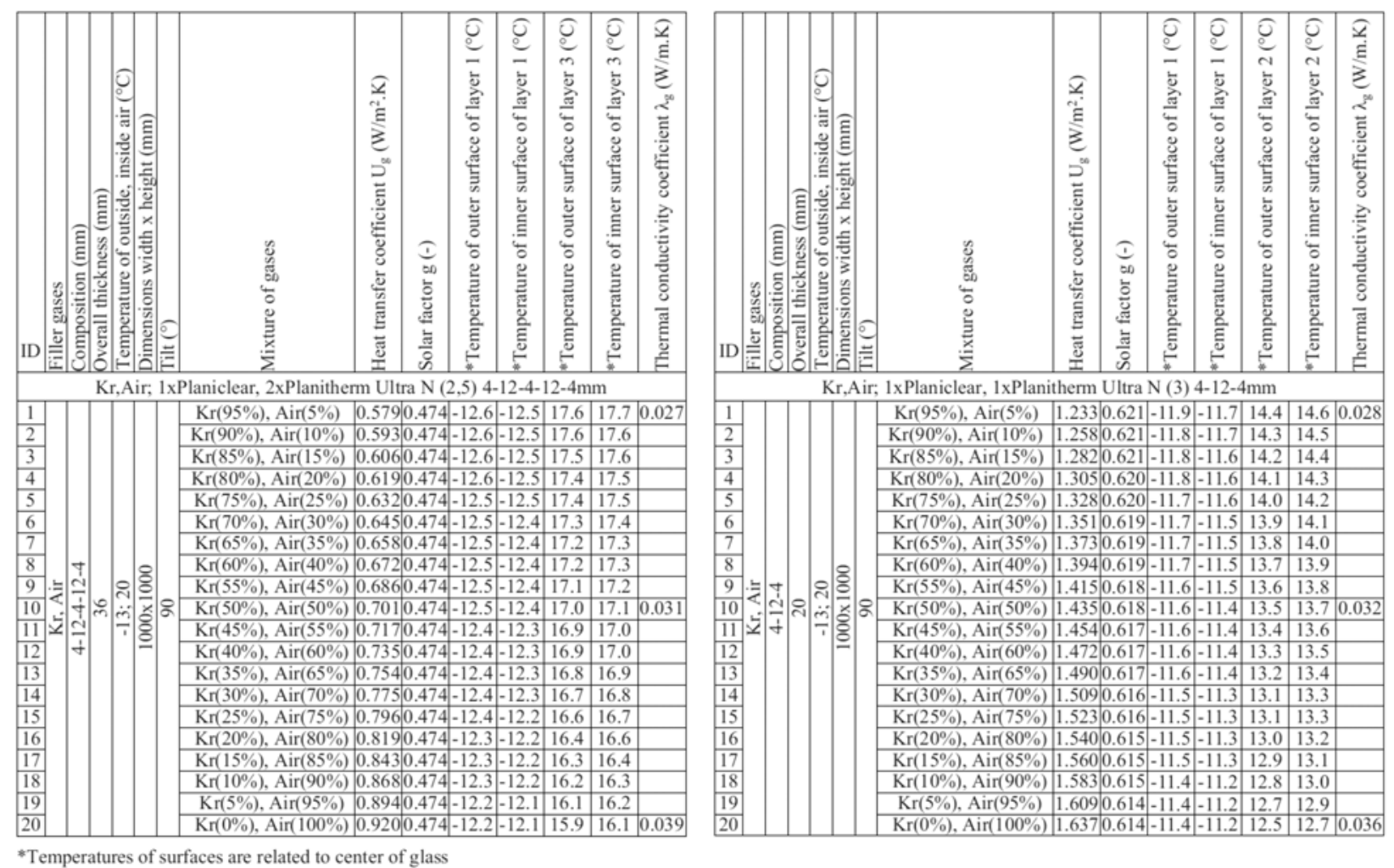

Table 5. Resulting differences between the initial and final heat transfer coefficient values

\begin{tabular}{lccc}
\hline $\begin{array}{l}\text { Glass } \\
\text { system }\end{array}$ & $\begin{array}{c}\text { Initial heat transfer coefficient } \\
U_{g(95 \%)}\left(\mathrm{W} / \mathrm{m}^{2} \cdot \mathrm{K}\right)\end{array}$ & $\begin{array}{c}\text { Final heat transfer coefficient } \\
U_{g(0 \%)}\left(\mathrm{W} / \mathrm{m}^{2} \cdot \mathrm{K}\right)\end{array}$ & $\begin{array}{c}\text { Difference between initial } \\
\text { and final } U_{g} \text { value }\left(\mathrm{W} / \mathrm{m}^{2} \cdot \mathrm{K}\right)\end{array}$ \\
\hline $\mathrm{A} 1$ & 0.878 & 0.878 & - \\
$\mathrm{A} 2$ & 1.612 & 1.612 & - \\
$\mathrm{B} 1$ & 0.703 & 0.920 & 0.217 \\
$\mathrm{~B} 2$ & 1.328 & 1.638 & 0.310 \\
$\mathrm{Cl}$ & 0.607 & 1.225 & 0.618 \\
$\mathrm{C} 2$ & 1.168 & 2.016 & 0.848 \\
\hline
\end{tabular}

fested in the case of Krypton insulating double glass system, where the gap between the glasses also plays a role compared to other cases of reduced thickness of $8 \mathrm{~mm}$.

In Table 4, there are rankings of the triple and double glass system filled with Krypton with a gap between glasses of $12 \mathrm{~mm}$ compared to $8 \mathrm{~mm}$ gap values. In the case of triple glass system, the initial value of heat transfer coefficient dropped from $0.607 \mathrm{~W} / \mathrm{m}^{2} \cdot \mathrm{K}$ to $0.579 \mathrm{~W} / \mathrm{m}^{2} \cdot \mathrm{K}$ (difference is 0.028 $\mathrm{W} / \mathrm{m}^{2} \cdot \mathrm{K}$ ), while the final value increased due to a decrease in Krypton concentration in the case of an $8 \mathrm{~mm}$ wide gap, a value of $1.225 \mathrm{~W} / \mathrm{m}^{2} \cdot \mathrm{K}$ and, in the case of a $12 \mathrm{~mm}$ wide gap, a value of $0.920 \mathrm{~W} / \mathrm{m}^{2} \cdot \mathrm{K}$ (difference is $0.305 \mathrm{~W} / \mathrm{m}^{2} \cdot \mathrm{K}$ ).

\section{Conclusion}

As a result of the demonstrable effect of decreasing gas concentration in the glass gap in the thermal performance of the glass system, selected concepts of glass systems differing in key parameters have been assessed. After the numerical analysis, one of the glass systems was assessed in simulation where a model with the same boundary conditions as the calculation was created in order to get as close as possible to the calculation and realistic conditions of the buildings to which the glass systems could be located. The resulting effect on the heat transfer coefficient is in some cases milder, in others more pronounced. Explaining the physical model with further simula- 


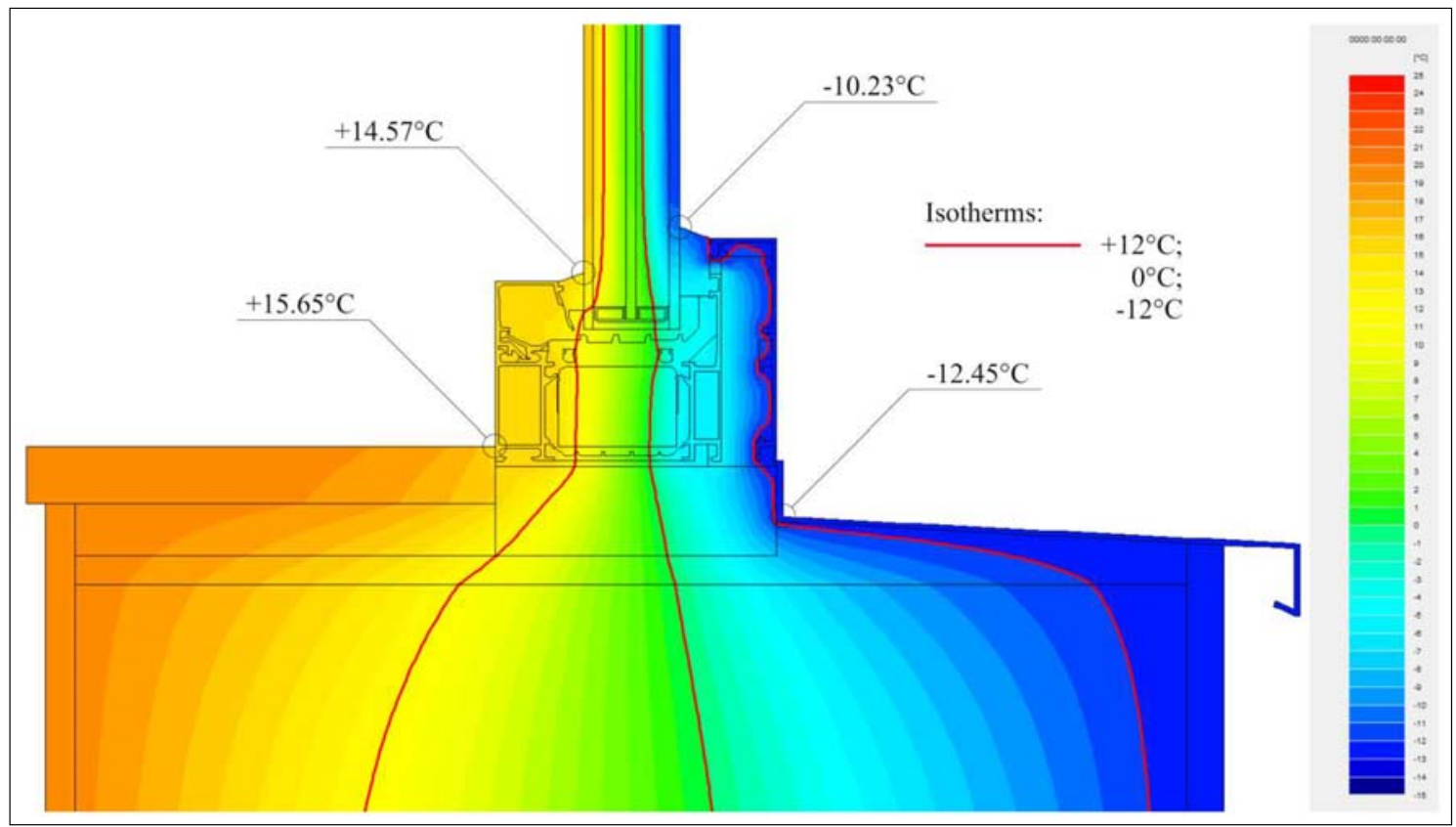

Fig. 4. Distribution of thermal field of air filled triple glass system (according to Fig. 3)

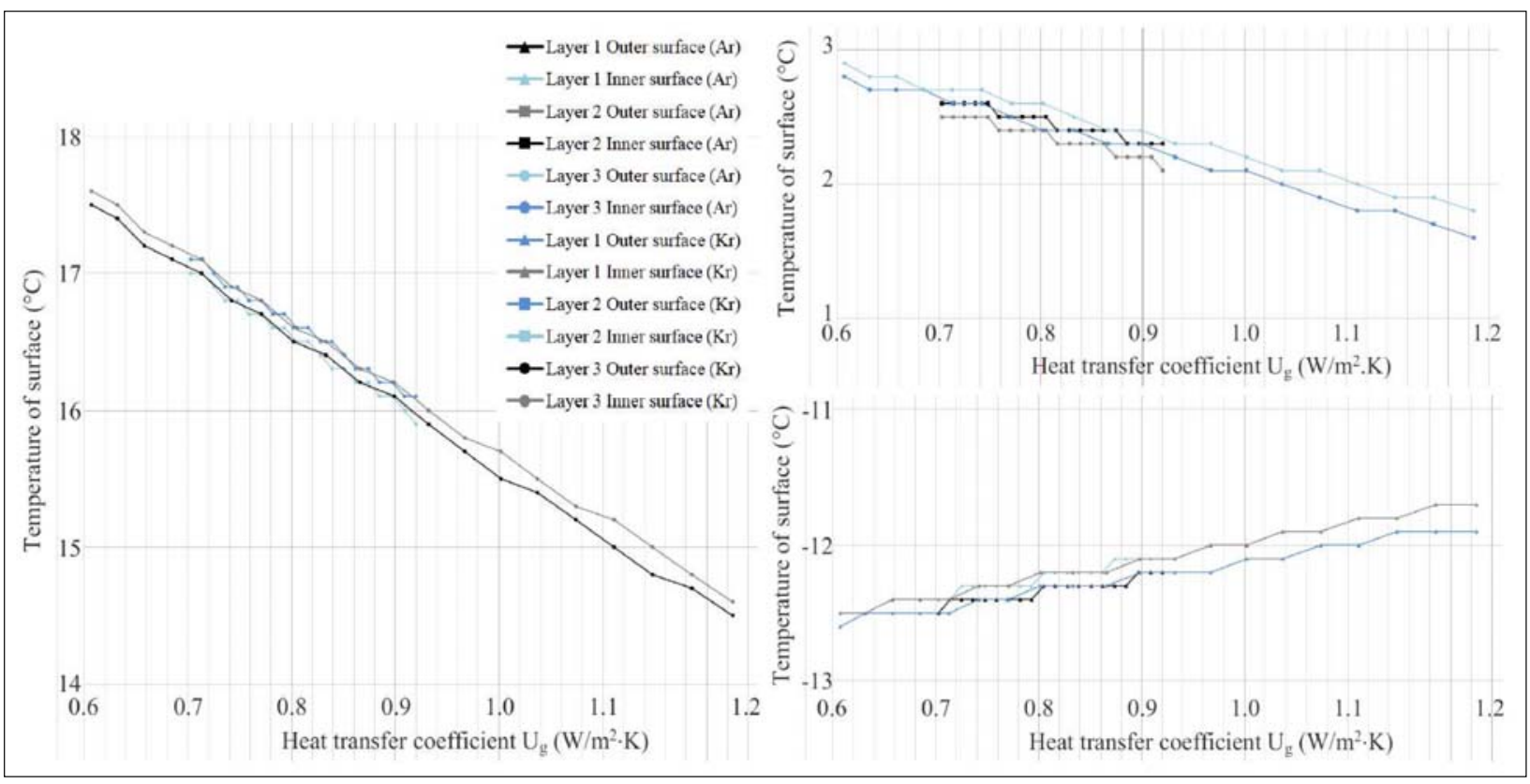

Fig. 5. Results of Argon filled triple glass system (B1) and Krypton filled triple glass system

tions leads to more accurate results applicable to further research.

\section{Acknowledgements}

This paper was created and realized with support of research project VEGA 1/0389/17 "Transparent construction in interaction of the contemporary architecture and on the human health".

\section{References}

[1] Standard STN EN 1279-3 (2004), Glass in building. Insulating glass units. Part 3: Long term test method and requirements for gas leakage rate and for gas concentration tolerances.

[2] Palko M. (2014), Physical assessment of a window using a computer simulation. Advanced Material Research, 855, 93-96. 
[3] Standard STN 73 0540-2/Z1 (2016), Thermal protection of buildings. Thermal performance of buildings and components. Part 2: Functional requirements.

[4] Standard STN EN 673 (2011), Glass in building. Determination of thermal transmittance (U value). Calculation method.

[5] Standard STN EN 674 (2011), Glass in building. Determination of thermal transmittance ( $U$ value). Guarded hot plate method.

[6] Standard STN EN 675 (2011), Glass in building. Determination of thermal transmittance ( $U$ value). Heat flow meter method.

[7] Chmúrny I., Puškár A., Panáček P. (2016), Thermal insulation properties of insulating glass. Slovenergookno.

[8] Gas space convection effects on $U$-values in insulating glass units. Glass technical document TD 101. Vitro, October 2016.
[9] Standard STN 73 0540-3 (2012), Thermal protection of buildings. Thermal performance of buildings and components. Part 3: Properties of environments and building products.

[10] Hens H. (2011), Applied building physics, boundary conditions, building performance and material properties. Berlin: Wilhelm Ernst \& Sohn. ISBN 978-3-433-02962-6.

[11] Zozulák M., Vertal’ M., Katunský D. (2014), Numerical analysis of window structure seating depth effects on surface temperature and linear thermal transmittance. Advanced Material Research, 1057, 53-60. ISSN 1022-6680.

[12] Window 7.4.14 (2017), NFRC Simulation manual, Lawrence Berkley laboratory.

[13] Physibel Software (2013), User manual for Physibel - Bistra. Maldegem, Belgium. 